\title{
INHALTSÜBERSICHT ÜBER DAS GESAMTWERK
}

Erster Band: Repräsentative Lebensbilder

I. Wildbeuter - II. Pfleger von Pflanzen und Tieren: A. Die Pfleger der Pflanzen (Feldbauer) - B. Die Pfleger von Vieh und die Hirten.

Zweiter Band: Familie.

I. Die Verzahnung von Geschlecht und Alter - II. Die Stellung der Frau - III. Die Verbindung von Mann und Frau - IV. Die Heirat - V. Sexuelle Sitten - VI. Das Problem der Heiratsordnung - VII. Verwandtschaft - VIII. Künstliche Verwandtschaft - IX. Das Mutterrecht - X. Das Vaterrecht - XI. Das Kind - XII. Der Altersablauf. - XIII. Die Bünde.

Dritter Band: Wirtschaft.

I. Die Wirtschaft (Die sozialpsychische Verflochtenheit der Wirtschaft - Methoden der Nahrungswirtschaft und der Organisation) - II. Die Wirtschaftsfunktionen.

Vierter Band: Werden, Wandel und Gestaltung von Staat und Kultur.

A) Gesellungsformen und ihr Wandel. I. Soziale Gestaltungen - II. Kräfte der Vergesellung im Männerverband - III. Das Funktionieren egalitärer Verbände - IV. Politische Gefüge - V. Führerschaft. - VI. Staatsbildung - VII. Kampf und Friede - VIII. Sklaverei - B) Kultur, Zivilisation und Gesellschaft. I. Siedlung - II. Wirtschaftshorizont, politische Gefüge und Familiengestaltung - III. Extremformen und Sondergestaltungen IV. Die Persönlichkeit in der Gesellschaft - V. Fortschritt und Zyklus - VI. Entwicklung, Rückstand, Variation und Ablauf - VII. Das Spiel der Kräfte, Gestaltung und Lebensprozeß von Gesellung und Zivilisation.

Fünfter Band: Recht.

I. Grondzüge des primitiven Rechtes - II. Das öffentliche Recht - III. Sachenrecht IV. Verbindlichkeiten - V. Der Erbgang - VI. Die Missetat und ihre Bestrafung VII. Der Rechtsstreit - VIII. Die Bedeutung der Herrschaft für das Recht und die „Gerechtigkeit".

Copyright 1935 by

Walter de Gruyter \& Co. vormals G. J. Göschen'sche Verlagshandlung - J. Guttentag, Verlagsbuchhandlung - Georg Reimer - Karl J. Trübner - Veit \& Comp.

Berlin und Leipzig.

Printed in Germany

Archiv.Nr. 420435

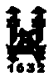

Drack von J. J. Anguatin in Glackstadt and Bamburg 